\title{
Optimum Switching Angle of Switched Reluctance Motor Using Response Surface Methodology
}

\author{
Agus Adhi Nugroho', Muhammad Khosyi'in ${ }^{2}$, Bustanul Arifin ${ }^{3}$, Bhakti Yudho Suprapto ${ }^{4}$, Muhamad \\ Haddin $^{5}$, Zainuddin Nawawi ${ }^{6}$ \\ 1,2,3,4,6 Dept. of Electrical Engineering, Universitas Sriwijaya Palembang, Indonesia \\ ${ }^{1,2,3,5}$ Dept. of Electrical Engineering, Universitas Islam Sultan Agung Semarang, Indonesia
}

\begin{abstract}
Article Info
\section{Article history:}

Received Aug 30, 2021

Revised Nov 25, 2021

Accepted Dec 16, 2021

\section{Keywords:}

switched reluctance motor optimum angles constant torque region response surface methodology

ABSTRACT

Switched Reluctance Motor has numerous advantages compared to another electric motor. Simple structure, low-cost production, robustness, and high fault tolerance have been remarkable milestones. Still, the problem of excitation angle at power converter becomes crucial, especially for traction use, requiring higher torque at low speed for starting and acceleration. Therefore, this research emphasized finding the optimum excitation angle at low speed using Response Surface Methodology, a practical application to achieve the highest torque, as indicated by the best speed in the constant torque region. As a result, using Matlab simulation, the adaptive combination of optimum angles reached $2691 \mathrm{rpm}$ quicker than a single excitation angle with $2568 \mathrm{rpm}$, an increase of $4.79 \%$ higher speed using RSM optimization. According to the experimental data, the adaptive combination of optimum angle achieved $2475 \mathrm{rpm}$ better than the single excitation angle reached 2340 rpm, an increase of $5.77 \%$ higher speed using the Response Surface Methodology.
\end{abstract}

Copyright (C) 2021 Institute of Advanced Engineering and Science. All rights reserved.

\section{Corresponding Author:}

Agus Adhi Nugroho,

Department of Electrical Engineering,

Universitas Islam Sultan Agung Semarang,

Kaligawe Raya Street Km.4 Semarang, Central Java 50112 ; PO Box 1054/SM Indonesia.

Email: agusadhi@unissula.ac.id

\section{INTRODUCTION}

Switched Reluctance Motor (SRM) has numerous advantages compared to previous electric motors. Simple structure with no winding construction in the rotor side, low cost due to the absence of permanent magnet robustness, and high fault tolerance. The ability to operate in a harsh environment and suitable for highspeed operation become better than other motors [1], [2], yet ideal for electric vehicles [3]-[5]. Another advantage of SRM is its firm structure, heat tolerance, fast response, high starting torque, high efficiency, and wide operating range become the other benefits [6], [7].

Besides the advantage of SRM, torque ripple, acoustic noise, and demand unique control requirements become the SRM weakness [8]-[10]. Moreover, one of the problems of SRM is the complex control of the electronic power converter used to feed the machines [11], and the excitation angle requires special consideration [12].

In the case of traction use, such as in an electric vehicle, the high torque at low speed becomes crucial for starting and acceleration. Therefore this research will focus on determining the turn-on and turn-off angle characteristic at low speed and how to find the best combination angle for high torque as indicated by the best speed achievement, especially for low speed using the Response Surface Methodology (RSM).

The torque generated in Switched Reluctance Motor depends on phase current, rotor, and stator position[4], [13]. The analytic (online) method used to improve and optimize the torque per ampere 
performance [10], [14], calculate the back electromotive force that is taken into account [15], [16], minimize the torque ripple [17]-[19], and efficiency optimization, etc. [9] [20]

There are methods to overcome SRM weakness according to the difficulties in controlling the converter to feed the machines. The analytic (online) process was applied in the Matlab/Simulink by directly inserting the turn-on and turn-off angle formulas to the block, and the simulation started. This method takes the back electromotive force (emf) into account and is simple in control, making it less expensive and easier to implement [16]. Still, it does not work correctly at low speed (below $5000 \mathrm{Rpm}$ ) [21]. Furthermore, the method removed the resistor, and the shape of the current profile was distorted [22].

The self-tuning (offline) method separates the simulation and the calculation to optimize the turn-on and turn-off-angle. In [23], the simulation is first to run in Matlab/Simulink, and then the result is optimized using a specific method. This method has several advantages over the analytic method (online). First, consider the back electromotive and stator resistor, resulting in more precise low and high speeds [16]. Second, the selftuning keeps the torque ripple minimized and achieves better performance than another method [13]. Third, the offline method achieves better efficiency and a lower torque ripple [24]. Longer simulation time and plenty of data to find the best combination angle become challenging tasks since spending much longer time and complex calculations using massive data.

The offline methods have been used to optimize several methods. There are Artificial Neural Networks [10], [25], Particle Swarm Optimization [11], [18], [26], 2D \& Hooke Jeeve Pattern [7]. The Response Surface Methodology (RSM) is used to determine the best turn-on and turn-off-angle combination. The same RSM method has already been used to determine an optimal design to find stable torque in Switched Reluctance Motor [19] and structural optimization to decrease torque ripple to suppress vibration and noise [27]. RSM is also used to determine suitable torque ripple, cogging torque, and Total Harmonic Distorsion from back electromagnetic in Permanent Magnet Synchronous Motor (PMSM) [28]. The RSM is used to determine the empiric model, performance, and design variable [29]. The Efficiency optimization approach, power factor, and optimum design process of single-phase SRM for vacuum cleaners using geometric and electrical parameters using RSM [20].

Since the torque of Switched Reluctance Motor depends on the phase current and the exact position of stator and rotor, the excitation angle, both turn on and turn off-angle, became the main parts in developing the shaft mechanical output (equation 3). The simulation using Matlab Simulink will prove that changing the turn-on and turn-off angle causes the speed achieved in the simulation to be different from each other with the same duration of time. Therefore, the adaptive optimum combination angle will reach better speed compared to a single excitation angle. Therefore, this research's hypothesis is to find the best excitation angle for low speed (constant torque region) using Response Surface Methodology (RSM) to find the best combination of turn on and turn off-angle, proved by the higher speed achieved.

\section{RESEARCH METHOD}

This research used RSM optimization to determine the best excitation angle (in constant torque region) at a low-speed range. Furthermore, the best combination angle, both turn-on and turn-off angle in constant torque region (low speed), were applied for electric drives such as in electric vehicles. Therefore, high torque at low speed became the main characteristic for traction application. The simulation data were collected using the self-tuning (offline) method using Matlab/Simulink 2018b, and the optimized angle was found using Response Surface Methodology. Then, the optimized excitation angle will be applied to the SRM.

The Switched Reluctance Motor specification data is 6/4 type SRM, six pole stator winding, and fourrotor poles. The data obtained from direct measurement is the stator resistance $0.5 \mathrm{ohm}$, aligned inductance 23.6. e-3 H, unaligned Inductance 0,898. e-3H, and the other data using the standard from Matlab Simulink.

The voltage equation of Switched Reluctance Motor:

$V=R \cdot i+L(\theta) \frac{d i}{d t}+i \frac{d L(\theta)}{d t} \omega$

$R, i, \theta, \lambda$, is resistance, current, rotor position, flux linkage.

Hence the energy equation of SRM :

$P=V i=R i^{2}+\frac{d}{d t}\left(\frac{1}{2} L i^{2}\right)+\frac{1}{2} i^{2} \frac{d L}{d \theta} \ldots \ldots$

The $R i^{2}$ denotes stator winding loss, the $\frac{d}{d t}\left(\frac{1}{2} L i^{2}\right)$ denotes the rate of change of magnetic stored energy, and the $\frac{1}{2} i^{2} \frac{d L}{d \theta} \omega$ denotes the mechanical output on the shaft. The most effective use of energy is maintained when the current remains constant during the positive slope of $\frac{d L}{d \theta}$. The torque production in the SRM is provided by the rotor's tendency to attain the position of minimum reluctance at exited stator phase. The instantaneous torque expression in each stage is [30]:

$$
T(\theta, i)=\frac{1}{2} i^{2} \frac{d L(\theta)}{d \theta}
$$




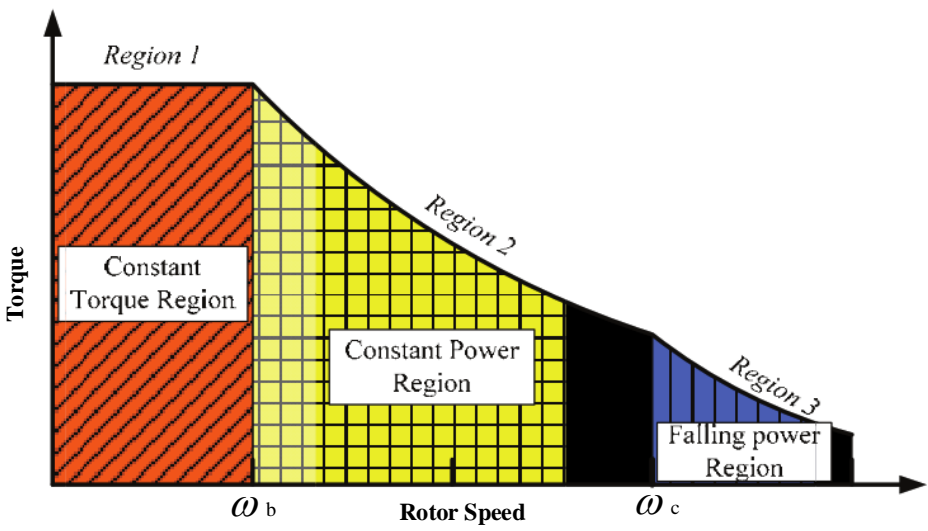

Figure 1. Torque speed characteristics of an SRM drive

Figure 1 depicts the three regions of the torque-speed characteristics [31]. The current chopping control (CCC) is where the constant torque region is positioned below the base speed $\left(\omega_{\mathrm{b}}\right)$ when the back EMF is lower than the DC source voltage because the magnitude of the back emf is small. Hence, the current rises quickly to reach the reference value of a hysteresis current controller. Finally, the highest speed at which the maximum rated current can be applied at rated voltage and fixed excitation angle is called the constant torque region [30].

The current decreases as the motor speed increases until the back emf equals DC bus voltage. Therefore, the turn-on angle advanced to keep the current rising to the desired level against the small back emf (lower speed). Another action that coincides with adjusting the turn-off angle to retain the dwell angle prevents braking torque [30].

Suppose the speed increases further and the back emf exceeds the DC bus voltage (high-speed operation). In that case, The current starts to decrease, and the turn-on and turn-off angles are adjusted to maintain dwell angles with the single pulse mode of operation. The controller keeps maintaining the torque inversely proportional to the speed. The turn-on angle advanced until it reached its maximum before the dwell angle reached the upper limit in the top position $\left(\omega_{c}\right)$. The scheme is called an advance angle control (AAC), where the constant power operation has a broader process to reach the higher speed called the constant power region.

When the dwell angle occupies half of the rotor pole pitch (half electrical cycle), it cannot increase any further because the flux would not return to zero, and the current conduction would become continuous. Therefore, the current and torque decrease since the back emf becomes more prominent. The torque in this region is governed by natural characteristics similar to those of the DC series motor (natural operation). The back emf is proportional to the current, and the torque is proportional to the current's square [1].

\subsection{Asymmetric Bridge Converter}

The converter uses the asymmetric bridge converter, as shown in Figure 2a, which can overlap the excitation and be controlled individually for every phase. The asymmetric bridge converter consists of two Mosfet and two Diodes in every phase. Therefore, it can be operated for magnetization and demagnetization [32].

The voltage pulse width modulation and current pulse width modulation control the converter. For example, Figure $2 \mathrm{~b}$ shows the upper switch $S_{1}$ and lower switch $S_{2}$ turning on (conduction state). First, the current Ia started to increase until it reached the upper limit of the hysteresis current controller. Then, both switches $S_{1}$ and $S_{2}$ are turned off, causing the current to decrease due to free-wheeling via the diodes $D_{1}$ and $D_{2}$, allowing the magnetic energy stored in the inductor returned to the DC source. Finally, when the current drops below the hysteresis band's a lower limit, the switch is turned back on until the conduction period is completed [1].

Since the back emf is small at low speeds, the speed below base speed $\omega_{\mathrm{b}}$ is called current chopping control. When the converter switches are turned on, the phase current rises and falls, with the hysteresis current controller limiting the rise and fall. The phase current is regulated at the rated value offering a constant torque operation. The turn-on and turn-off angles should coincide with the rotor positions $\theta_{1}$ and $\theta_{2}$ of the positive slope region of the phase inductance. It is necessary to turn in advance $\theta_{\text {on }}$ by $\theta_{1}-\theta_{\text {on }}$ and also the $\theta_{\text {off }}$ by $\theta_{2}-\theta_{\text {off }}$ as depicted in Figure 3, both advanced angles are dependent on the phase current and also the rotor speed. 

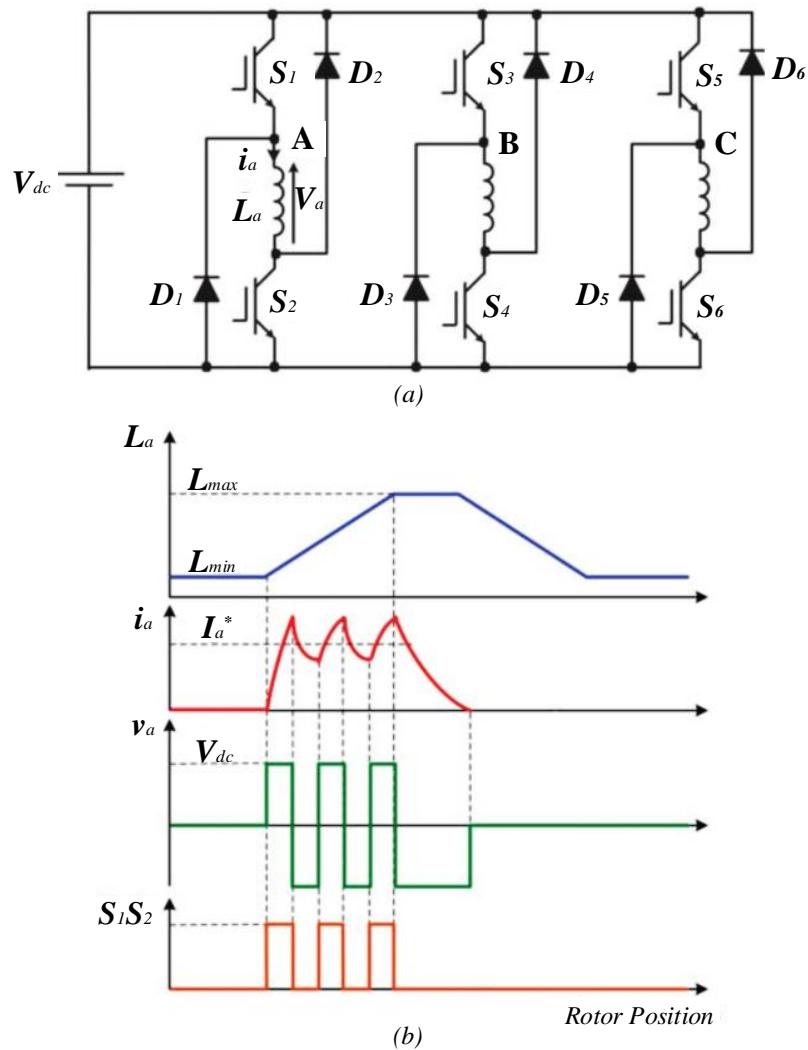

Figure 2. Three-phase asymmetric bridge converter (a) topology and (b) operating waveform

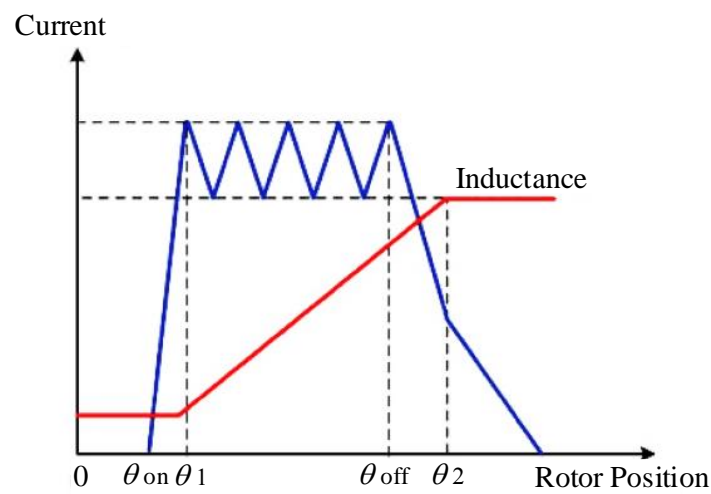

Figure 3. Current chopping control for low-speed operation

\subsection{Response Surface Methodology}

Response surface methodology is a practical application in developing an approximation model for the proper response surface. The approximation is empirically based on observed data from the existing system. RSM is built by statistical technique collection employing multiple regression to develop, improve, and optimize processes. Response surface methodology is used to design, develop, and form new products and improve existing product designs. According to RSM, many factors are considered critical factors and regions of interest where the factor influencing the outcome is known, the factors that vary continuously throughout the experimental range are tested, and a mathematical function relates to the factors to the measured response [33].

Figure 4 explains the RSM flow to find the optimum switching angle. The angle of SRM in every simulation step was determined using RSM with two free variables ( $\theta_{\text {on }}$ and $\theta_{\text {off }}$ angle) to achieve the highest speed. The central composite design uses two order $2 \mathrm{k}$ factorial, resulting in 12 simulations for central composite design (CCD). First, the simulation will be run for the constant torque region (low speed) with a 
starting time of 0.5 seconds and increasing by 0.5 seconds. The maximum current was reached when the simulation was terminated according to the definition of constant torque [30]. Then, methodological tests such as analysis of variance (ANOVA) were applied to test the data optimised by the RSM. It is used to find the best fit if some tests, such as Model Response, must be significant. The Lack of Fit must be insignificant, adjusted $R^{2}$ and predicted $R^{2}$ for a reasonable agreement must be less than 0,2 , and the last is the adequate precision must be higher than 4 . The combination angle must be recombined again if the model does not meet those requirements [33]. The simulation and test should then be repeated.
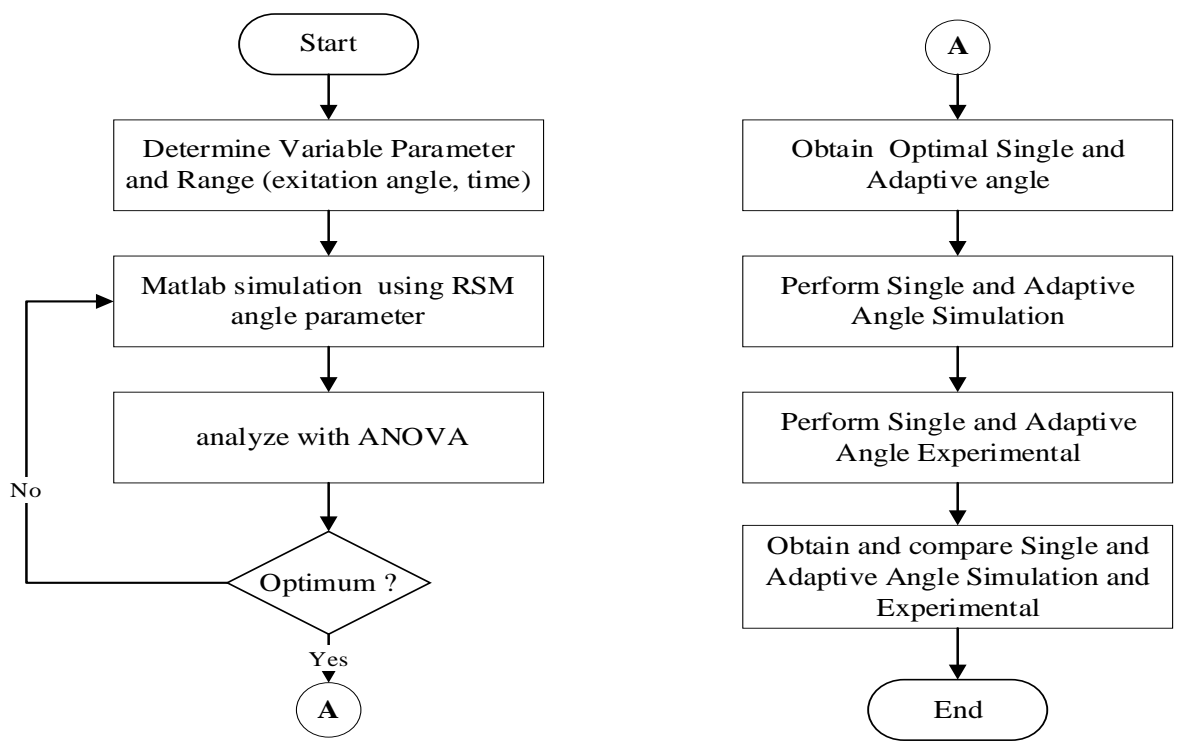

Figure 4. The RSM simulation and experimental procedure

After providing the optimum of single and adaptive angles, the Matlab simulation started for both single and adaptive angles simulations to find the maximum speed. The single and adaptive angles were then applied to the SRM experiment to find the top speed. Finally, the comparison of simulation and experiment speed will be used to analyze the RSM performance.

\section{RESULTS AND ANALYSIS}

The SRM used in the simulation is a 6/4 (six stator poles and four-rotor poles), 12 volts with a threephase asymmetric bridge converter. The direct measurement of stator resistance is $0.5 \mathrm{ohm}$, aligned inductance 23.6. ${ }^{\mathrm{e}-3} \mathrm{H}$, unaligned Inductance 0.898 . $\mathrm{e}^{-3} \mathrm{H}$, and the other data using the standard data from Matlab Simulink.

\subsection{Constant Torque Region}

The constant torque region is the highest speed when the maximum rated current is applied to the motor at the rated voltage. The constant torque region position indicated by the current shape changed from current limited by hysteresis current limiter (with ripples) to single pulse current (with no ripples), as depicted in Figure 5. As a result, the current tends to decrease around $t=8.55$ seconds (rounded to 9 seconds) and become the boundary for the simulation time to find the optimum excitation angle within this constant torque region $\omega_{\mathrm{b}}$. Therefore, the constant torque region is the lowest possible speed for the motor to operate at its rated power, as stated in Figure 1 [31].

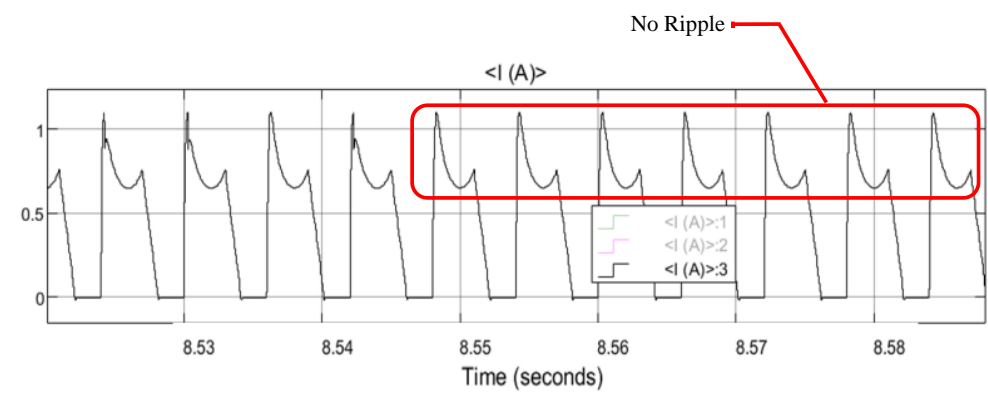

Figure 5. Current shape in the base speed $\omega_{\mathrm{b}}$ 


\subsection{Optimum Switching Angle}

The single excitation angle for comparison using the $\theta_{\text {on }}$ and $\theta_{\text {off }}$ angle starting from 45 degrees for $\theta_{\text {on }}$ and 90 degrees for $\theta_{\text {off. }}$ The simulation continued to find the best torque as indicated by the higher speed that could be achieved for the same duration time of the simulation. The simulation started from 0.5 seconds and increased to another 0.5 seconds every time. To determine the highest speed of this simulation using central composite design with two orders and 2k factorial of Response Surface Methodology with trial and error method until the tests met the criteria, such as Model Response (F-value), must be significant. Furthermore, the Lack of Fit must be insignificant, the adjusted $\mathrm{R}^{2}$ and predicted $\mathrm{R}^{2}$ for a reasonable agreement must be less than 0,2 , and the adequate precision must be higher than 4 . The first simulation started for 0.5 -second simulation and combination of angle using the Response Surface Methodology found 45-degree $\theta_{\text {on }}$, and 90degree $\theta_{\text {off }}$ and the group of couple angle $\left(\theta_{\text {on }}\right.$ and $\left.\theta_{\text {off }}\right)$ using two order and $2 \mathrm{k}$ factorial design of RSM described in Table 1 are as follows :

Table 1. Simulation angle with RSM.

\begin{tabular}{cccc}
\hline No & Turn on angle & Turn off angle & Speed (Rpm) \\
\hline 1 & 43 & 88 & 212.5 \\
2 & 47 & 88 & 212.4 \\
3 & 43 & 92 & 212.9 \\
4 & 47 & 92 & 212.8 \\
5 & 42.1716 & 90 & 211.8 \\
6 & 47.8284 & 90 & 211.8 \\
7 & 45 & 87.1716 & 212.8 \\
8 & 45 & 92.8284 & 214 \\
9 & 45 & 90 & 214 \\
10 & 45 & 90 & 214 \\
11 & 45 & 90 & 214 \\
12 & 45 & 90 & 214 \\
\hline
\end{tabular}

Then the simulation result was tested to see if the optimal speed for the combination angle met the RSM requirement. The table was then analyzed with analysis of variance (ANOVA) for quadratic model $2 \mathrm{k}$ factorial for the speed response as stated in Table 2. The Model F value represents the measurement of significance of the overall ANOVA model, with 91 points indicating that the model is significant. An F value this large could occur due to noise only $0.01 \%$ of the time. Therefore, the higher the F value, the better the model. The value of $\mathrm{P}$ represents the probability value of 0.001 , which is less than 0.05 , indicating that the model terms are significant.

Table 2. ANOVA for quadratic model

\begin{tabular}{ccccccc}
\hline Source & Sum of Squares & df & Mean Square & F-value & p-value & \\
\hline Model & 8.39 & 5 & 1.68 & 91.00 & $<0.0001$ & Significant \\
A-turn on & 0.0050 & 1 & 0.0050 & 0.2713 & 0.6211 & \\
B-turn off & 0.7794 & 1 & 0.7794 & 42.29 & 0.0006 & \\
AB & 0.0000 & 1 & 0.0000 & 0.0000 & 1.0000 & \\
$\mathrm{~A}^{2}$ & 7.57 & 1 & 7.57 & 410.66 & $<0.0001$ & \\
$\mathrm{~B}^{2}$ & 0.5290 & 1 & 0.5290 & 28.70 & 0.0017 & \\
Residual & 0.1106 & 6 & 0.0184 & & & \\
Lack of Fit & 0.1106 & 3 & 0.0369 & & & \\
Pure Error & 0.0000 & 3 & 0.0000 & & & \\
Cor Total & 8.50 & 11 & & &
\end{tabular}

The value of $\mathrm{B}, \mathrm{A}^{2}, \mathrm{~B}^{2}$ are significant model terms, and if these values are greater than 0.1000 , the value indicates that the model terms are not significant. If their values are many insignificant model terms (not including those required to support hierarchy), the model reduction may improve.

Table 3 indicates that the value of Predicted $\mathrm{R}^{2}=0.9074$ reasonably corresponds to the value of Adjusted $\mathrm{R}^{2}=0.9761$, indicating that the difference between Predicted $\mathrm{R}^{2}$ and Adjusted $\mathrm{R}^{2}$ is less than 0.2. The Adequate Precision value measures the ratio of signal to noise and the point 23.025 (greater than 4), indicating that the signal is adequate, which means that this model can be used to navigate the design space. 


\begin{tabular}{cccc}
\multicolumn{4}{c}{ Table 3. Fit Statistics } \\
\hline Std. Dev. & 0.1358 & $\mathrm{R}^{2}$ & 0.9870 \\
Mean & 213.08 & Adjusted R & 0.9761 \\
C.V. \% & 0.0637 & Predicted R $^{2}$ & 0.9074 \\
& & Adeq Precision & 23.0249 \\
\hline
\end{tabular}

Table 4. Coefficients in Terms of Coded Factors

\begin{tabular}{ccccccc}
\hline Factor & Coefficient Estimate df Standard Error & 95\% CI Low & $95 \%$ CI High & VIF \\
\hline Intercept & 214.00 & 1 & 0.0679 & 213.83 & 214.17 & \\
A-turn on & -0.0250 & 1 & 0.0480 & -0.1425 & 0.0925 & 1.0000 \\
B-turn off & 0.3121 & 1 & 0.0480 & 0.1947 & 0.4296 & 1.0000 \\
AB & 0.0000 & 1 & 0.0679 & -0.1661 & 0.1661 & 1.0000 \\
$\mathrm{~A}^{2}$ & -1.09 & 1 & 0.0537 & -1.22 & -0.9562 & 1.04 \\
$\mathrm{~B}^{2}$ & -0.2875 & 1 & 0.0537 & -0.4188 & -0.1562 & 1.04 \\
\hline
\end{tabular}

Table 4 state the coefficient in terms of coded factors. When all other factors are held constant, the Coefficient Estimate represents the expected change in response per unit change in factor value when all remaining factors are kept constant. The intercept in an orthogonal design is all the runs' overall average response, the coefficients adjusted around that average based on the factor settings. When the factors are orthogonal, the Variance Inflation Factors (VIFs) are 1. If the value of VIFs greater than 1 indicates multicollinearity, the higher the VIF value, the more severe the correlation of factors. And as a general rule, the value of VIFs less than 10 points is tolerable.

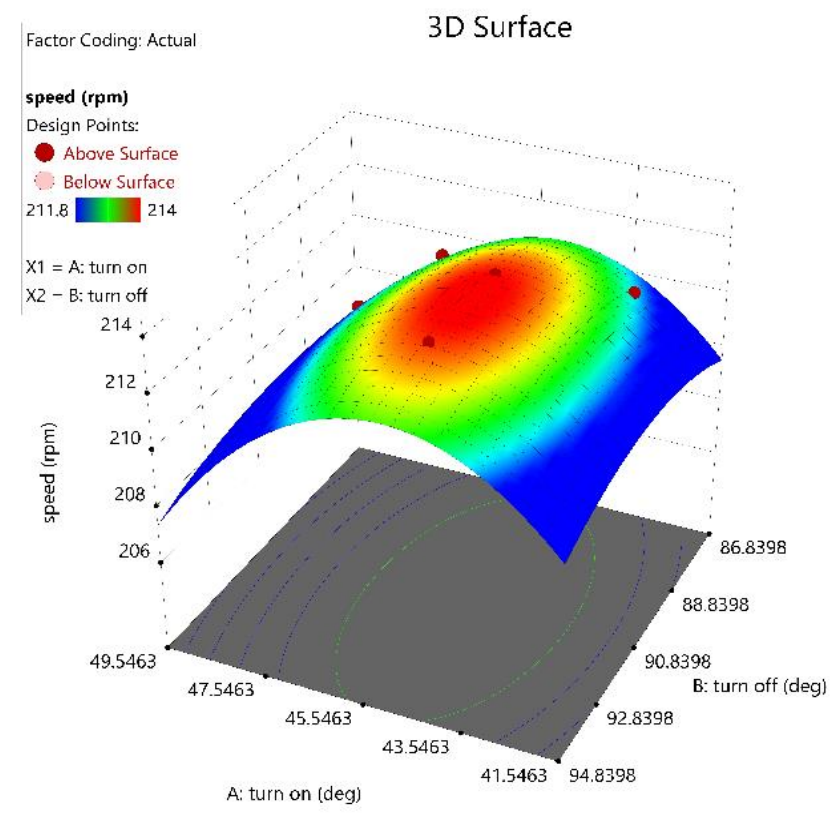

Figure 6. Response surface plot for optimum switching angle

The response surface plot for the optimum angle at 0.5 second simulation time is depicted in Figure 6. The image shows the optimum angle found in the combination of 45 degrees for turn-on angle and 90 degrees for turn-off angle, and the rotor speed reached $214 \mathrm{rpm}$. The speed is optimal for 0.5 second simulation time. It has already been tested and fit for some tests, such as Model Response (F-value), the Lack of Fit, adjusted $\mathrm{R}^{2}$ and predicted $\mathrm{R}^{2}$, and the adequate precision all fulfill the requirement.

The simulation time then extends to 1.5 seconds, 3 seconds, 4 seconds, 6 seconds, and the last is 9 seconds. The excitation angles were changed by varying amounts for every group simulation time until the optimum angle was found and finally tested using the ANOVA to ensure convergence speed.

The combination of angles and speed results for all simulation time stated in Table 5 are as follows: 


\begin{tabular}{ccccccccc}
\multicolumn{8}{c}{ Table 5. Maximum speed at an optimum angle (rpm) } \\
\hline \multirow{2}{*}{$\mathrm{t}$ on } & $\mathrm{t}$ off & \multirow{2}{*}{ Dwell } & \multicolumn{6}{c}{ Duration of simulation (second) } \\
\cline { 6 - 10 }$(\mathrm{deg})$ & $(\mathrm{deg})$ & angle & 0.5 & 1.5 & 3 & 4 & 6 & 9 \\
\hline \multirow{2}{*nnnnyyyyy}{45.00} & 90.00 & 45.00 & $\mathbf{2 1 4 . 0 0}$ & 630.10 & $1,212.00$ & $1,530.00$ & $2,031.00$ & $2,568.00$ \\
45.00 & 88.00 & 43.00 & 213.60 & $\mathbf{6 3 1 . 4 0}$ & $1,222.00$ & $1,550.00$ & $2,071.00$ & $2,636.00$ \\
44.78 & 87.44 & 42.66 & 213.60 & 631.40 & $\mathbf{1 , 2 2 3 . 0 0}$ & $1,550.00$ & $2,071.00$ & $2,569.00$ \\
44.66 & 86.44 & 41.78 & 213.20 & 630.80 & $1,221.00$ & $\mathbf{1 , 5 5 5 . 0 0}$ & $2,078.00$ & $2,668.00$ \\
44.66 & 85.00 & 40.34 & 209.30 & 620.50 & $1,214.00$ & $1,551.00$ & $\mathbf{2 , 0 9 2 . 0 0}$ & $2,682.00$ \\
44.33 & 84.44 & 40.11 & 210.10 & 622.80 & $1,216.00$ & $1,553.00$ & $2,090.00$ & $\mathbf{2 , 6 8 6 . 0 0}$ \\
\hline
\end{tabular}

The highest speed for single excitation angle at 45 degrees turn on, and 90 degrees turn off for 9 seconds simulation time was $2568 \mathrm{rpm}$. The speed will be compared to the adaptive optimum excitation angle. The adaptive optimum excitation angle will be simulated with Matlab, shifting the angle for every speed change.

The first step in setting up an adaptive excitation angle is to excite using 45 degrees turn-on and 90 degrees turn-off, and when the speed reaches $214 \mathrm{rpm}$, the excitation angle shifts to 45 degrees turn-on and 88 degrees turn-off. Once the speed reached $631.4 \mathrm{rpm}$, the excitation angle shifted to 44.78 degrees turn-on and 87.44 degrees turn-off. Once the speed reached $1223 \mathrm{rpm}$, the excitation angle changed to 44.66 degrees turnon and 86.44 degrees turn-off. Once the speed reached $1555 \mathrm{rpm}$, the excitation angle changed to 44.66 degrees turn-on and 85 degrees turn-off. Once the speed reached $2092 \mathrm{rpm}$, the excitation angle changed to 44.33 degrees turn-on and 84.44 degrees turn-off.

Then the adaptive excitation angle is simulated, and the highest simulation speed is achieved, 2691 rpm., a higher speed than a single excitation angle (at 45 degrees and 90 degrees) that reaches only $2568 \mathrm{rpm}$ for the same duration simulation time for 9 seconds. The speed achieved shows that combining an optimum angle given by the RSM method achieves a higher speed of $123 \mathrm{rpm}(4.79 \%)$ than a single excitation angle. Furthermore, the torque produced by the adaptive combination of optimum excitation angle gains higher torque as indicated by the higher speed achieved.

\subsection{Experimental Result}

The switched reluctance motor for the experimental system setup is seen in Figure 7. The SRM with six pole stators and four-pole rotors controlled with a three-phase asymmetric bridge converter is connected to a 12 volt DC 32 ampere power supply. DSPIC 30F4012 is the microchip used to control the excitation of the MOSFET.

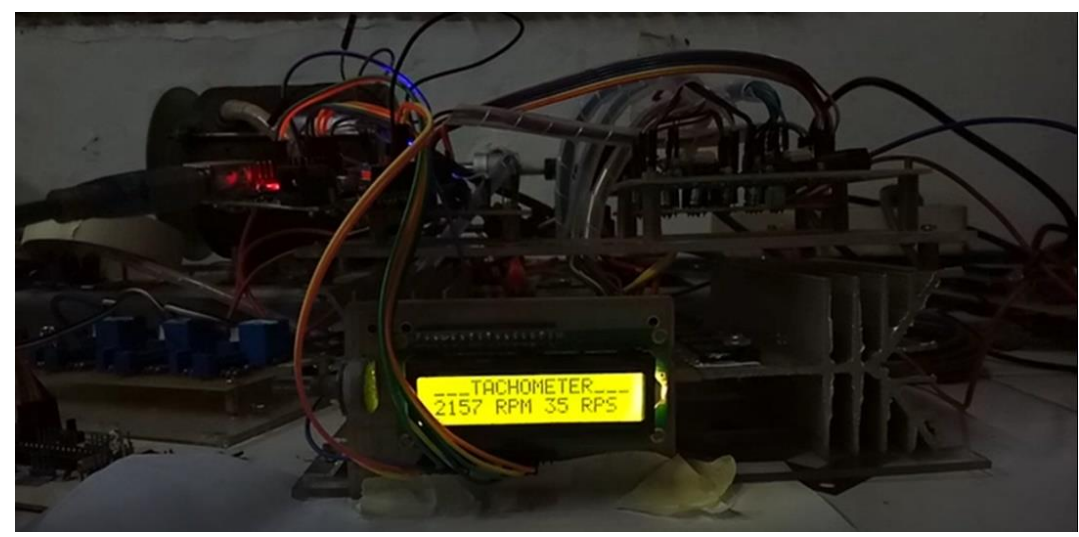

Figure 7. Switched reluctance motor experimental system

The first running experiment was done with a single excitation angle using a 45-degree turn-on angle and 90 degrees for turn-off-angle. According to the constant torque region, the average speed for 9 seconds duration time reached averaged $2340 \mathrm{rpm}$. 
The experiment was carried out using adaptive angles from the Matlab simulation described above. First, start the couple angle turn-on and turn-off from 45 degrees to 90 degrees after the speed reaches $214 \mathrm{rpm}$. Next, the angle shifts to 45 degrees turn-on and 88 degrees turn off when the speed comes $631 \mathrm{rpm}$, then the angle shift to 44.78 degrees turn-on and 87.44 turn-off when the speed reaches 1223, the angle shift to 44.66 degrees turn-on and 86.44 turn-off when the speed reaches $1555 \mathrm{rpm}$. Then the angle shifts to 44.66 turn-on, and 85 degrees turn-off when the speed reaches $2092 \mathrm{rpm}$, and the last is the shift to 44.33 degrees turn-on and 84.44 turn-off. The duration of simulation time is 9 seconds, as stated in Table 6.

The first run was done with a single excitation angle using a 45-degree turn-on angle and 90 degrees for turn-off-angle. According to the constant torque region, the average speed for 9 seconds duration time reaches around $2340 \mathrm{rpm}$.

Table 6. Running the experiment of Single and adaptive excitation angle

\begin{tabular}{rcc}
\hline No & Single Excitation angle (rpm) & Adaptive excitation angles (rpm) \\
\hline 1 & 2334 & 2480 \\
2 & 2348 & 2466 \\
3 & 2340 & 2478 \\
4 & 2336 & 2475 \\
5 & 2348 & 2465 \\
\hline Average & 2340 & 2475 \\
\hline
\end{tabular}

The adaptive excitation angle applies in the RSM to adaptively change the turn-on and turn-off angles relating to the speed. The experiment shows that the combination of adaptive angles gains more torque as indicated by a higher achieved speed of $2475 \mathrm{rpm}$ than the single excitation angle that only reaches $2340 \mathrm{rpm}$, $5.77 \%$ more speed using the Response Surface Methodology. The experimental equipment result shows the same behavior as the Matlab simulation applied with adaptive optimum excitation angle to achieve a higher speed.

\section{CONCLUSION}

According to traction applications such as in electric vehicle use, the high torque at low speed becomes crucial since starting and acceleration. Therefore, the starting region, known as the constant torque region, was determined at around 9 seconds.

The SRM simulation for a single excitation angle reaches $2568 \mathrm{rpm}$, while the adaptive combination excitation angle of SRM simulation reaches $2691 \mathrm{rpm}$, an increase of $4.79 \%$ of the speed than a single excitation angle.

The experimental data show that adaptive combination excitation angles achieve better torque, as indicated by the higher speed at 2475 than single excitation angles at $2340 \mathrm{Rpm}$, an increase of $5.77 \%$ of the speed than a single excitation angle.

Furthermore, the experimental data show that using Response Surface Methodology to find the best adaptive combination excitation angles is achieved.

The following research will conduct a similar method for constant power operation and natural operation.

\section{ACKNOWLEDGMENT}

This paper is supported by Universitas Islam Sultan Agung and Universitas Sriwijaya

\section{REFERENCES}

[1] Kwok Tong Chau, Electric Vehicle Machines and Drives Design, Analysis and Application, First Edit. Singapore: John Wiley \& Sons (Asia) Pte Ltd, 2015.

[2] M. Takeno et al., "Test Results and Torque Improvement of the 50-kW Switched Reluctance Motor Designed for Hybrid Electric Vehicles," IEEE Trans. Ind. Appl., vol. 48, no. 4, pp. 1327-1334, 2012.

[3] S. Muthulakshmi and R. Dhanasekaran, "Intelligent Controller Based Speed Control of Front End Asymmetric Converter fed Switched Reluctance Motor," 2016 Int. Conf. Adv. Commun. Control Comput. Technol., no. 978, pp. 426-431, 2016.

[4] S. M. Castano and J. Maixe, "Torque Control Optimization of a Switched Reluctance Motor Drive for a 42V Automotive Application," in 2007 IEEE International Symposium on Industrial Electronics, 2007, pp. 1171-1176.

[5] J. L. Beniwal and R. K. Tripathi, "Speed Control of SRM Drives using a New Power Converter Configuration in Electric Vehicles," in 2014 Australasian Universities Power Engineering Conference (AUPEC), 2014, no. October, pp. 1-6. 
[6] H. Chen, Q. Wang, and H. H.-C. Iu, "Acceleration Closed-Loop Control on Switched Reluctance Linear Launcher," IEEE Trans. Plasma Sci., vol. 41, no. 5, pp. 1131-1137, 2013.

[7] X. D. Xue et al., "Optimal Control Method of Motoring Operation for SRM Drives in Electric Vehicles," IEEE Trans. Veh. Technol., vol. 59, no. 3, pp. 1191-1204, 2010.

[8] R. Krishnan, Switced Reluctance Motor Drivers: Modeling, Simulation, Analysis, Design, and Applications. CRC Press, 2017.

[9] X. Gao, X. Wang, Z. Li, and Y. Zhou, "The Design of Switched Reluctance Motor Torque Optimization Controller," Int. J. Control Autom., vol. 8, no. 5, pp. 27-36, 2015.

[10] M. Hamouda and L. Számel, "Optimum Control Parameters of Switched Reluctance Motor for Torque Production Improvement over the Entire Speed Range," Acta Polytech. Hungarica, vol. 16, no. 3, pp. 79-99, 2019.

[11] Thi Mai Phuong Dao, Y. N. Wang, and N. K. Nguyen, "A Novel Control Approach For Switched Reluctance Motors Based On Fuzzy Logic And Particle Swarm Optimization Techniques," Univ. Politeh. Bucharest Sci. Bull. Ser. CElectrical Eng. Comput. Sci., vol. 78, no. 3, pp. 85-96, 2016.

[12] J. Larminie and J. Lowry, Electric Vehicle Technology Explained. John Wiley \& Sons, 2012.

[13] R. Orthmann and H. P. Schoner, "Turn-Off Angle Control of Switched Reluctance Motors for Optimum Torque Output," in 1993 Fifth European Conference on Power Electronics and Applications, 1993, pp. 20-25, Vol 6.

[14] C. Lin and B. Fahimi, "Optimisation of commutation angles in SRM drives using FRM," in 2012 IEEE Transportation Electrification Conference and Expo (ITEC), 2012, pp. 1-6.

[15] M. Hamouda and L. Számel, "A New Technique for Optimum Excitation of Switched Reluctance Motor Drives Over a Wide Speed Range," Turkish J. Electr. Eng. Comput. Sci., no. 26, pp. 2753-2767, 2018.

[16] Y. Z. Xu, R. Zhong, L. Chen, and S. L. Lu, "Analytical Method to Optimise Turn-On Angle and Turn-Off Angle for Switched Reluctance Motor Drives," IET Electr. Power Appl., vol. 6, no. 9, pp. 593-603, 2012.

[17] D. Cajander and H. Le-huy, "Design and optimisation of a torque controller for a switched reluctance motor drive for electric vehicles by simulation," vol. 71, pp. 333-344, 2006.

[18] V. V. Prabhu, V. Rajini, M. Balaji, and V. Prabhu, "A Comparative Study of Operating Angle Optimization of Switched Reluctance Motor with Robust Speed Controller using PSO and GA," vol. 10, 2015.

[19] J. H. Choi, D. J. Kim, Y. Do Chun, P. W. Han, D. H. Koo, and J. Lee, "Approximate optimisation for minimum torque ripple of three phase switched reluctance motor using response surface modeling," Int. J. Appl. Electromagn. Mech., vol. 39, no. 1-4, pp. 825-833, 2012.

[20] J. Choi, D. Koo, S. Kim, Y. Kim, and J. Ahn, "Approximate optimisation for maximum efficiency of high speed single phase switched reluctance motor using response surface modelling," vol. 28, pp. 227-235, 2008.

[21] M. Hamouda and L. Számel, "Optimum Excitation Angles for Switched Reluctance Motor Drives," XXXIII. Kandó Conf. Óbudai Univ., pp. 128-142, 2017.

[22] M. Hamouda and L. Szamel, "Torque Control of Switched Reluctance Motor Drives for Electric Vehicles," in Proceedings of the Automation and Applied Computer Science Workshop, 2017, pp. 9-20.

[23] X. Wang, Z. Yang, T. Wang, and D. He, "Design of A Wide Speed Range Control Strategy of Switched Reluctance Motor for Electric Vehicles," no. August, pp. 294-299, 2015.

[24] A. M. Omekanda, "A New Technique for Multidimensional Performance Optimisation of Switched Reluctance Motors for Vehicle Propulsion," IEEE Trans. Ind. Appl., vol. 39, no. 3, pp. 672-676, 2003.

[25] B. Fahimi, G. Suresh, J. P. Johnson, M. Ehsani, M. Arefeen, and I. Panahi, "Self-Tuning Control of Switched Reluctance Motors for Optimised Torque Per Ampere at All Operating Points," in APEC '98 Thirteenth Annual Applied Power Electronics Conference and Exposition, 1998, no. Vol. 2, pp. 778-783.

[26] J. Mukherjee and S. Chowdhuri, "Multiobjective Optimisation by PSO for Switched Reluctance Motor (SRM) Drive," in 2014 11th International Conference on Informatics in Control, Automation and Robotics (ICINCO), 2014, pp. 391-396.

[27] C. Huang and G. Yang, "Optimization Design of Switched Reluctance Motor Based on Response Surface Method," 2018 IEEE Student Conf. Electr. Mach. Syst., pp. 1-6, 2018.

[28] S. I. Kim, G. H. Lee, J. J. Lee, and J. P. Hong, "Simple Design Approach For Improving Characteristics of Interior Permanent Magnet Synchronous Motors for Electric Air-Conditioner Systems in HEV," Int. J. Automot. Technol., vol. 11, no. 2, pp. 277-282, 2010.

[29] L. Qinghua, M. A. Jabbar, and A. M. Khambadkone, "Response Surface Methodology Based Design Optimisation Of Interior Permanent Magnet Synchronous Motors For Wide-Speed Operation," Second Int. Conf. Power Electron. Mach. Drives (PEMD 2004), vol. 2, no. 6, pp. 546-551, 2004.

[30] I. Husain, "Switched reluctance machines," in The Power Electronics Handbook: Industrial Electronics Series, 1st ed., T. L. Skvarenina, Ed. CRC Press, 2002, pp. 1-20.

[31] J.-W. Ahn, "Switched Reluctance Motor," in Torque control, vol. i, no. 8, Moulay Tahar Lamchich, Ed. Janez Trdine 9, 51000 Rijeka, Croatia: InTech, 2011, pp. 201-252.

[32] S. Riyadi, "Control Strategy for Switched Reluctance Motor With Rotary Encoder Based Rotor Position," Adv. Electr. Electron. Eng., vol. 16, no. 3, pp. 261-270, 2018.

[33] D. C. R. H. M. Montgomery, Response-Surface-Methodology. Published by John Wiley \& Sons, Inc., Hoboken, New Jersey, 2009. 


\section{BIOGRAPHY OF AUTHORS}

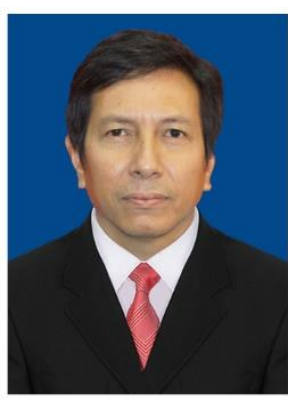

Agus Adhi Nugroho was born on August 28th 1965 in Semarang (Central Java , Indonesia). He is a graduate of Universitas Diponegoro (UNDIP) Semarang in electrical engineering. His postgraduate program is in Electrical Engineering at Gadjahmada University Jogjakarta. And in recent years, he has taken the doctoral program of Electrical Engineering at the Sriwijaya University of Palembang. In addition, he is an academic staff of Electrical Engineering of the Sultan Agung Islamic University of Semarang as a lecture and concerns in electric machines and energy management. His last paper is "Load Effect on Switched Reluctance Motor Using Hysteresis Current and Voltage Control" in 2021 8th International Conference on Electrical Engineering, Computer Science and Informatics (EECSI).

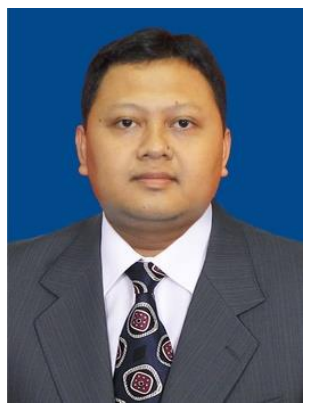

Muhammad Khosyi'in was born on July 25th, 1979, in Jepara (Central Java, Indonesia). Graduate of Sultan Agung Islamic University (UNISSULA) Semarang in electrical engineering. His postgraduate program in Electrical Engineering at Sepuluh Nopember Institute of Technology, Surabaya. And in recent years, he has taken the doctoral program of Electrical Engineering at the Sriwijaya University of Palembang. He is an academic staff of Electrical Engineering of the Sultan Agung Islamic University of Semarang. He is concerned about major control and monitoring systems, electrical instrumentation, and sensor actuator systems. His last paper is "Tests Measurement of UHF RFID for Autonomous Vehicle Navigation" in the International Seminar on Application for Technology of Information and Communication (iSemantic). IEEE, 2020.

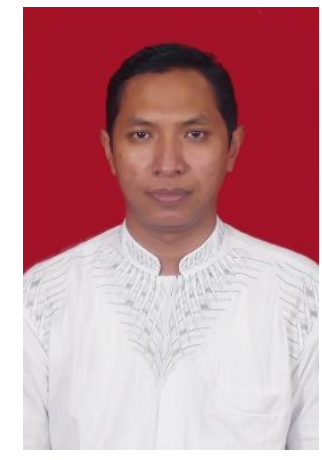

Bustanul Arifin was born on November 14th, 1977, in Semarang (Central Java, Indonesia). Graduate of Sultan Agung Islamic University (UNISSULA) Semarang in electrical engineering. His postgraduate program is in Electrical Engineering from Gadjah Mada University. And in a recent year, he takes the doctoral program of Electrical Engineering at the Sriwijaya University of Palembang. He is an academic staff of Electrical Engineering of the Sultan Agung Islamic University of Semarang, concerned with major control and monitoring system, electrical instrumentation, and sensor-actuator system. His last paper is "The lateral control of autonomous vehicles: A review" at the 2019 International Conference on Electrical Engineering and Computer Science (ICECOS).

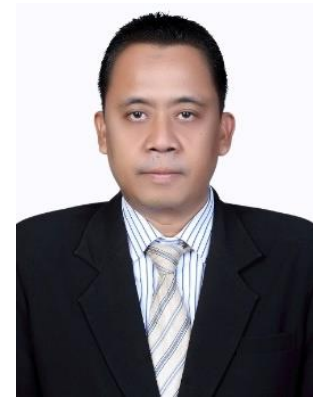

Bhakti Yudho Suprapto was born on February 11th 1975 in Palembang (South Sumatra, Indonesia). He is a graduate of the Sriwijaya University of Palembang in electrical engineering, postgraduate and doctoral program is in Electrical Engineering of Indonesia University (UI) of Jakarta. He is an academic staff of Electrical Engineering of the Sriwijaya University of Palembang. He is concerned with major control and intelligent system. His last paper is "Identification of Garbage in the River Based on The YOLO Algorithm" in the International Journal of Electronics and Telecommunications, 2021. 


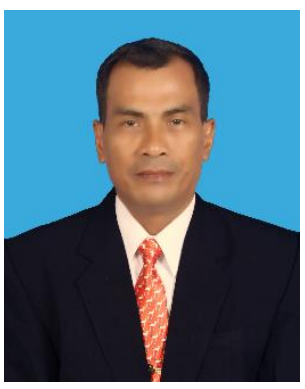

Muhamad Haddin was born in Semarang, 18th Juni 1963. He is lecterur in Sultan Agung Islamic University Semarang. The electrical engineering background is from Diponegoro University, graduated from Gadjah Mada University, then continued his doctoral program in electrical engineering at Institut Teknologi Sepuluh November Surabaya. He graduated in 2013, and His last paper is "Fuzzy logic applications for data acquisition systems of practical measurement" in the International Journal of Electrical and Computer Engineering (IJECE).

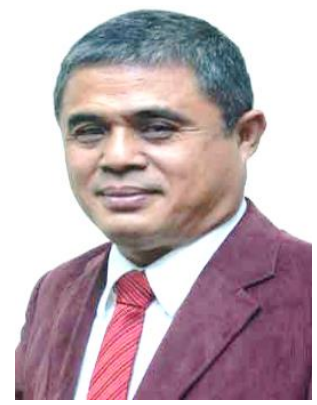

Zainuddin Nawawi was born on March 3rd 1959 in Lubuklinggau (South Sumatra, Indonesia). $\mathrm{He}$ is a graduate of the Sriwijaya University of Palembang with a major in electrical engineering. His postgraduate and doctoral program is in Electrical Engineering of Technology University of Malaysia (UTM). He is an academic staff of Electrical Engineering of the Sriwijaya University of Palembang. He is concerned about the major protection material. He is one of the Electrical Engineering Professor at Sriwijaya University. His last paper is "Remote Water Quality Monitoring with Early-Warning System for Marine Aquaculture" in E3S Web of Conferences (Vol. 324, p. 05007). EDP Sciences 